\title{
Use of Asthma APGAR Tools in Primary Care Practices: A Cluster-Randomized Controlled Trial
}

Barbara P. Yawn, MD, MSc1

Peter C. Wollan, $\mathrm{PbD}^{1}$

Matthew A. Rank, $M D^{2}$

Susan L. Bertram, RN, MSN ${ }^{1}$

Young Jubn, MD, MPH

Wilson Pace, $M D^{4}$

'Department of Research, Olmsted Medical

Center, Rochester, Minnesota

${ }^{2}$ Division of Allergy, Asthma, and Clinical Immunology, Mayo Clinic, Scottsdale, Arizona

${ }^{3}$ Department of Pediatrics and Adolescent Medicine, Asthma Epidemiology Research Unit, Mayo Clinic, Rochester, Minnesota

${ }^{4}$ National Research Network, American Academy of Family Physicians, Leawood, Kansas

Conflicts of interest: Barbara P. Yawn served on asthma and COPD advisory boards for Boebringer Ingelheim, GlaxoSmithKline, Novartis, and Teva. Young Jubn received support for astbma research from Genentech. All other authors report no conflicts of interest.

\section{CORRESPONDING AUTHOR}

Barbara P. Yawn, MD, MSc

University of Minnesota

1963 112th Cir NE

Blaine, Minnesota 55449

byawn47@gmail.com

\begin{abstract}
PURPOSE The purpose of this study was to assess patient and practice outcomes after introducing the Asthma APGAR (Activities, Persistent, triGGers, Asthma medications, Response to therapy) tools into primary care practices.
\end{abstract}

METHODS We used a pragmatic cluster-randomized controlled design in 18 US family medicine and pediatric practices to compare outcomes in patients with persistent asthma aged 5 to 45 years after introduction of the Asthma APGAR tools vs usual care. Patient outcomes included asthma control, quality of life, and emergency department (ED), urgent care, and inpatient hospital visits. The practice outcome was adherence to asthma guidelines.

RESULTS We enrolled 1,066 patients: 245 children, 174 adolescents, and 647 adults. Sixty-five percent (692 patients) completed both baseline and 12-month questionnaires, allowing analysis for patient-reported outcomes. Electronic health record data were available for 1,063 patients (99.7\%) for practice outcomes. The proportion of patients reporting an asthma-related ED, urgent care, or hospital visit in the final 6 months of the study was lower in the APGAR practices vs usual care practices (10.6\% vs $20.9 \%, P=.004)$. The percentage of patients with "in control" asthma increased more between baseline and 1 year in the APGAR group vs usual care group (13.5\% vs $3.4 \%, P=.0001$ vs $P=.86$ ) with a trend toward better control scores and asthma-related quality of life in the former at 1 year $(P \leq .06$ and $P=.06$, respectively). APGAR practices improved their adherence to 3 or more guideline elements compared with usual care practices $(20.7 \%$ increase vs $1.9 \%$ decrease, $P=.001$ ).

CONCLUSIONS Introduction of the Asthma APGAR tools improves rates of asthma control; reduces asthma-related ED, urgent care, and hospital visits; and increases practices' adherence to asthma management guidelines.

Ann Fam Med 2018;16:100-110. https://doi.org/10.1370/afm.2179.

\section{INTRODUCTION}

A sthma is a common chronic condition, ${ }^{1-3}$ and primary care is the site of most asthma diagnoses and management. ${ }^{2-5}$ Implementation of asthma guidelines has been challenging, and the burden of asthma remains high with little improvement from 1990 to $2010 .^{6-13}$

Use of a metric for assessing asthma control has been suggested for improving asthma care, and several asthma control scores have been developed and validated against allergists' assessments. ${ }^{14-25}$ But use of these tools remains limited and has not significantly improved asthma outcomes. ${ }^{23,26-36}$

The Asthma APGAR (Activities, Persistent, triGGers, Asthma medications, Response to therapy) (Figure 1) tools were developed not only to provide a score for asthma control, but also to guide further evaluation of inadequate control with a link to a care algorithm (Supplemental Figure 1, available at http://www.annfammed.org/content/16/2/100/suppl/ DC1/). In a small pilot study, use of the Asthma APGAR tools was associated with enhanced asthma guidelines adherence, and focus groups of patients and clinical staff reported that the tools were easy to use, "made 
sense," and "improved care." 37 The Asthma APGAR control score has been validated against the Asthma Control Test (ACT). ${ }^{38}$

Herein we present results of our large pragmatic cluster-randomized trial comparing introduction of the Asthma APGAR tools with usual care. We hypothesized that introducing these tools would improve patient outcomes and practices' adherence to asthma guidelines. We also explored the barriers to and facilitators of implementation in the study practices.

\section{Figure 1. Asthma APGAR patient form.}

$$
\begin{aligned}
& \mathbf{A}=\text { Activities } \\
& \mathbf{P}=\text { Persistent } \\
& \mathbf{G}=\text { triGGers } \\
& \mathbf{A}=\text { Asthma medications } \\
& \mathbf{R}=\text { Response to therapy }
\end{aligned}
$$

APGAR PLUS

$$
\begin{aligned}
& \mathbf{P}=\text { Asthma Plan } \\
& \mathbf{L}=\text { Lung function } \\
& \mathbf{U}=\text { Use of inhaler } \\
& \mathbf{S}=\text { Steroids }
\end{aligned}
$$

Please circle your answers:

1. In the past 2 weeks, how many times did any breathing problems (such as asthma) interfere with your ACTIVITIES or activities you wanted to do?
Never
$1-2$ times
3 or more times

2. How many DAYS in the past 2 weeks did you have shortness of breath, wheezing, chest tightness, cough or felt you should use your rescue inhaler?

3. How many NIGHTS in the past 2 weeks did you wake up or have trouble sleeping due to coughing, shortness of breath, wheezing, chest tightness or get up to use your rescue inhaler?
None
1-2 NIGHTS
3 or more NIGHTS

4. Do you know what makes your breathing problems or asthma worse?
Yes
No
Unsure

- Please circle the things that make your breathing problems or asthma worse:

Cigarettes Smoke Cold Air Colds Exercise
Cats Dogs $\quad$ Mold $\quad$ Other:

- Can you avoid the things that make your breathing problems or asthma worse?
Seldom
Sometimes
Most of the time

5. List or describe medications you've taken for breathing problems or asthma in the past 2 weeks. Remember you may use nasal, oral, or inhaler medications.

\begin{tabular}{|l|l|l|l|l|}
\hline $\begin{array}{c}\text { Breathing or } \\
\text { asthma medication }\end{array}$ & \multicolumn{2}{|c|}{ When taken? } & $\begin{array}{c}\text { Reasons for } \\
\text { taking medication }\end{array}$ & $\begin{array}{c}\text { Reasons for not } \\
\text { taking medication }\end{array}$ \\
\hline & $\square$ Daily & $\square$ As needed & & \\
\hline & $\square$ Daily & $\square$ As needed & & \\
\hline & $\square$ Daily & $\square$ As needed & & \\
\hline
\end{tabular}

6. When I use my breathing or asthma medicines I feel:
Worse
No different
A little better
A lot better 
Figure 2. CONSORT diagram for cluster-randomized trial of APGAR tools implementation in primary care.

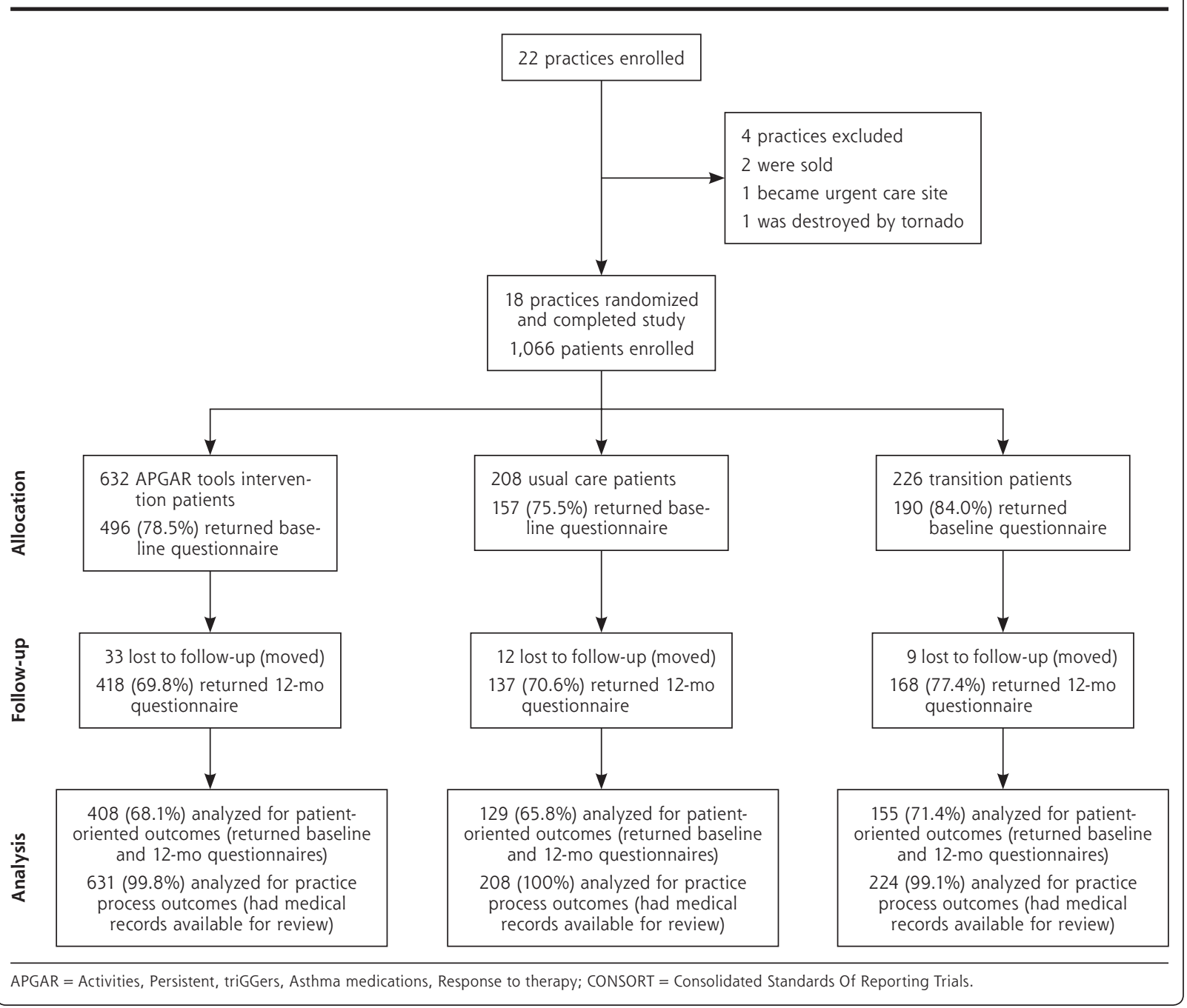

Our study was completed in practice-based research networks (PBRNs), which are particularly suitable settings for translational research. ${ }^{39-43}$ The purpose of the study was to facilitate selection of tools to improve asthma care and outcomes in the primary care setting. $27,28,44,45$

\section{METHODS}

\section{Study Design}

We undertook a pragmatic, cluster-randomized controlled effectiveness trial with crossover to intervention for all practices at study midpoint (Figure 2) that was completed in 18 family medicine and pediatric PBRN members. The study methods have been published previously. ${ }^{46}$ Of the 22 practices enrolled, 18 practices (9 intervention and 9 usual care randomized by practice size, practice type, and being a residency training site) completed the study. Three practices were lost before enrolling any patients ( 2 were sold and 1 became an urgent care site), and a 4th practice enrolled only 10 patients before being destroyed in a tornado.

The trial's coprimary endpoints were patient-reported asthma control using the ACT for adults and the child version (C-ACT) for children, ${ }^{17,18}$ and asthma-related quality of life using the Asthma Quality of Life Questionnaire (AQLQ) for adults or the pediatric version (PAQLQ) for children. ${ }^{25} \mathrm{We}$ also assessed changes in the proportion of patients reporting asthma-related emergency department (ED) visits, urgent care visits, or inpatient hospital visits (hospitalizations). Data were collected by questionnaires mailed to the patients at baseline, 6 months, and 12 months. Because of the pragmatic nature of the study, no study visits were required. All asthma visits and care were at the discretion of the patient and their chosen health care professionals. The study was powered to detect a 3-point difference in ACT scores, ${ }^{47}$ assuming a $65 \%$ survey response rate at 12 months. 
Secondary outcomes were changes in practice documentation of adherence to elements of the 2007 National Asthma Education and Prevention Program (NAEPP) US asthma guidelines ${ }^{14}$ assessed by research staff review of medical records. Exploratory outcomes were facilitators of and barriers to implementation of the Asthma APGAR tools reported by the practice staff during exit interviews.

Institutional review board approval was obtained for each practice, the Olmsted Medical Center, and the American Academy of Family Physicians. All patients and practice staff signed informed consent forms.

\section{Intervention: Asthma APGAR Tools}

The Asthma APGAR tools include a patient-completed asthma control assessment covering 5 domains: activity limitations (A/activity), daytime and nighttime symptom frequency $(\mathrm{P} /$ persistence of symptoms), asthma triggers $(\mathrm{G} /$ triGGers), adherence to asthma medications (A/adherence), and patient-perceived response to therapy (R/response to therapy) (Figure 1). The assessment is linked to a care algorithm that goes beyond simple "step up" therapy ${ }^{48}$ (Supplemental Figure 1, available at http://www.annfammed.org/content/16/2/100/ suppl/DC1/). Scores of greater than 2 on the activities and persistence questions are consistent with lack of asthma control. ${ }^{38}$ During training, practices requested that a further set of questions be developed to facilitate expansion on patients' responses such as adherence evaluation. No attempt was made to validate this "practical practice" tool (Supplemental Figure 2, http://www. annfammed.org/content/16/2/100/suppl/DC1).

\section{Study Practices}

The enrolled practices were members of the American Academy of Family Physicians National Research Network (NRN) (http://www.aafp.org/nrn) or the American Academy of Pediatrics Quality Improvement Innovation Network (QuIIN) (http://quiin.aap.org) and were selected to provide broad geographic coverage of the United States (Supplemental Figure 3, http:// www.annfammed.org/content/16/2/100/suppl/DC1). Practices had not previously engaged in asthma quality improvement and were instructed not to begin other asthma projects during the study period. Each practice was given $\$ 1,300$ annually for 4 years in recognition of practice participation. Randomization was by practice.

\section{Study Patients}

Patients were recruited either by invitation at an asthma visit or by letter and telephone contact after identification using billing data that recorded at least 2 visits for asthma (International Classification of Diseases, Ninth Revision codes 493.xx). The patient enrollment process and the data collected were the same regardless of the practice's assigned group, and patients were unaware of their practice's randomization status.

Children younger than 5 years were excluded to avoid the asthma diagnostic uncertainty often found in preschool children. ${ }^{49,50}$ Adults older than 45 years were also excluded because of concerns of chronic obstructive pulmonary disease (COPD) misdiagnosed as asthma and the Asthma COPD Overlap Syndrome (ACOS), for which treatment, disease progression, and diagnostic evaluations differ from those for asthma. ${ }^{51,52}$ Individuals with other chronic lung diseases were also excluded. Spirometry testing was not required to confirm the asthma diagnosis. ${ }^{53-55}$ All patients were reported to have persistent asthma requiring daily maintenance medication.

\section{Study Procedures}

Centralized training was directed to 2 "trainers" from each practice (a physician and a nursing staff member) who returned to the practice and trained the rest of their practice members. Trainers were provided slides, handouts, and telephone support to facilitate practice site training. They also completed human subjects training (http://www.citiprogram.org). Usual care sites received a short asthma overview and training regarding study procedures. Intervention sites received this training plus an additional 6 hours regarding the use and interpretation of the Asthma APGAR tools. The intervention was to be used in all patients with asthma, but data collection was limited to enrolled patients.

As designed in the protocol, at approximately 18 months into the study, all usual care sites were crossed over to the APGAR tools intervention. The crossover practices' trainers attended a short second centralized training session that addressed only the intervention. The trainers returned to educate their practice members on the intervention.

\section{Data Collection}

Patient-reported outcomes were collected by questionnaires using validated instruments for asthma control and asthma-related quality of life: the ACT and the C-ACT ${ }^{17,18}$ for asthma control, and the AQLQ and PAQLQ for asthma-related quality of life. ${ }^{56}$ Data collected at baseline and 12 months were used in analyses to account for potential seasonal variations that might be present at other intervals. Questions regarding health care use were adapted from those in the National Health Interview Survey. ${ }^{57}$ Questionnaires were returned by mail to the central site. Nonrespondents received a mailed reminder in 10 days, a second copy of the questionnaire in 21 days, and a telephone call at 28 days. 
Medical record data were used to assess the practice's guideline adherence. Prestudy assessments have been published previously. ${ }^{6}$ Each enrolled patient's medical records were obtained from his or her enrolling practice from 1 year before enrollment through study completion, and were copied and mailed to the central site for abstracting by trained nurse abstractors using a standardized form. The nurse abstractors evaluated documentation of asthma control assessment, factors affecting control (medication adherence, inhaler technique review, trigger assessment), patient self-management support (asthma action plan ${ }^{25,26}$ ), and the prescribing of both a quick relief and a maintenance medication. ${ }^{7,28}$ Nurse abstractors' intrarater and interrater reliability were assessed repeatedly and maintained at $95 \%$ agreement or higher..$^{58}$

Semistructured telephone exit interviews were completed for all sites to explore barriers to and facilitators of Asthma APGAR implementation. Interview questions are available on request.

\section{Data Analysis}

Because of the transition of usual care practices to the APGAR tools intervention, some patients' practices changed from usual care to the intervention during their enrollment period. To account for this change, patients were divided into 3 groups: usual care patients (completed 12 months of care while their practice was in usual care arm), APGAR tools intervention patients (completed 12 months of care while their practice was in the intervention arm), and transition patients (visited their practice during both its usual care and intervention periods). Primary outcomes analyses were completed comparing only usual care and intervention patients on an intention-to-treat basis. Subanalyses are presented by age-group for some outcomes to illustrate differences that occurred across age-groups. Analyses for practice adherence to guidelines included all enrolled patients regardless of whether they made visits during the study period.

For all outcomes, we compared frequencies between intervention and usual care at 12 months after patient enrollment for patient outcomes and at the end of each practice's period of enrollment in either the usual care or intervention study arm. For patient outcomes, we also assessed changes in frequency within study arms at baseline and 12 months using the $\chi^{2}$ and McNemar tests. Association of practice and patient characteristics with rates of asthma-related ED, urgent care, and hospital visits as well as the number of guideline elements assessed was tested using logistic regression analysis with a random effects term for practice sites to address any clustering effect. We used the S-Plus statistics package version 7.0.6 (Tibco Software) for all computations.

\section{RESULTS}

Overall, 1,066 patients were enrolled (Figure 2). Of those enrolled, $79.1 \%$ (843 patients) returned their baseline questionnaire and $68.0 \%$ (723 patients) returned their 12 -month questionnaire; $65.0 \%$ (692 patients) returned both, allowing their data to be used for patient outcomes. On the basis of medical records data, respondents and nonrespondents differed only on response rates, which were lower in adult men compared with women $(P=.0005) .{ }^{59}$ Medical records data were available for 1,063 (more than 99\%) of the enrolled patients for assessment of practice outcomes.

Characteristics of the patients who returned their baseline questionnaire are shown in Table 1 by their practice's randomization. Supplemental Table 1 (http://www.annfammed.org/content/16/2/100/ suppl/DC1) displays demographics by randomization and age-group. In general, patients were white, had modest family income (51.7\% less than $\$ 50,000$ per year), had inadequate asthma control, were often overweight, and had considerable exposure to tobacco smoke. During the 6 months before enrollment, the percent of patients reporting an asthma-related ED, urgent care, or hospital visit did not differ by randomization status. The enrolled practices' baseline adherence levels to asthma guidelines were very limited and have been described previously. ${ }^{6}$

\section{Patient Outcomes}

During the final 6-month period of enrollment, the proportion of patients reporting an asthma-related visit to the ED, urgent care, or hospital was a significant $51 \%$ lower in the APGAR tools intervention group compared with the usual care group (10.6\% vs $20.9 \%$, $P=.004)$. Relative to the 6 months before study enrollment, the proportion declined in the intervention group (from $17.5 \%$ to $10.6 \%, P=.001$ ) but increased in the usual care group (from $15.9 \%$ to $20.9 \%$, $P=.06$ ) (Figure 3). Findings by age-group were similar (Supplemental Figure 4, http://www.annfammed.org/ content/16/2/100/suppl/DC1). The difference remained significant in logistic regression models controlling for age-group; sex; race; income; ethnicity; the patient's previous asthma-related ED, urgent care, or hospital visits $_{\text {; }}$ and random effects adjustment for practice, with an odds ratio of 2.1 (95\% CI, 1.01 to $4.2, P=.04)$ (Supplemental Table 2, http://www.annfammed.org/ content/16/2/100/suppl/DC1).

The proportion of patients with "in control" asthma at 12 months trended toward improvement in the APGAR tools intervention group as compared with the usual care group $(54.3 \%$ vs $46.0 \%, P \leq .06)$. The proportion with controlled asthma increased significantly between baseline and 12 months in the former group 
(from $40.8 \%$ to $54.3 \%, P<.0001$ ) but not in the latter group (from $42.6 \%$ to $46.0 \%, P=.86$ ) (Figure 3 ).

Changes in asthma-related quality-of-life scores showed a trend toward higher scores at 12 months in the APGAR tools intervention group vs usual care group, with mean scores of 5.37 vs 5.14 , respectively $(P=.07)$, which became significant after adjusting for multiple factors including patients' age, sex, race, and ethnicity, and a practice variable $(P=.04)$. The proportion of patients with a gain of at least 0.5 points (minimally clinically significant change) between baseline and 12 months also showed a trend toward improvement in the APGAR tools intervention group vs usual care group (36.6\% vs $27.0 \%$, respectively, $P=.07$ ).

\section{Practice Outcomes}

The APGAR tools intervention practices had an improvement in adherence to nonmedication guideline elements by 12 months compared with the usual care practices $(P<.001$ for adherence to 3 or more elements of the guidelines) (Supplemental Table 3, http://www.annfammed. org/content/16/2/100/suppl/ DC1). This difference between groups remained significant when controlling for multiple factors using random effects adjustment for practice difference; patients' age, sex, race, and ethnicity; and baseline adherence to guideline elements, with an odds ratio of 3.89 (95\% CI, 1.87 to $8.07, P$ $<$.001) (data not shown).

Medication prescribing improved in both groups, with increases in rates of prescription of daily asthma medication (Supplemental Table 4, http://www.annfammed.org/ content/16/2/100/suppl/DC1). The intervention group had a smaller share of patients with inadequate asthma therapy (no daily controller or no shortacting $\beta_{2}$ agonist) prescribed at 12 months compared with the usual care group $(14.7 \%$ vs $8.2 \%, P=.03)$.

\section{Exploratory Outcomes}

Exit interviews with study coordinators and clinicians highlighted several barriers to and facilitators of implementing the Asthma APGAR tools (Table 2). Although practice change was reported as difficult, clinicians and practice staff who used the tools found them helpful. Both physicians and nursing staff reported that learning and determining how to implement the new system required additional time and practice, but they thought that it rapidly "streamlined" asthma visits. Implementing the Asthma APGAR tools became a priority and may have delayed working on other practice improvements for at least the first year of the study.

\section{Table 1. Baseline Patient Characteristics}

\begin{tabular}{|c|c|c|c|c|}
\hline Characteristic & $\begin{array}{l}\text { APGAR Tools } \\
\text { Group } \\
(n=496)\end{array}$ & $\begin{array}{l}\text { Usual Care } \\
\text { Group } \\
(n=157)\end{array}$ & $\begin{array}{l}\text { Transition } \\
\text { Group } \\
(\mathbf{n}=190)\end{array}$ & $\begin{array}{l}\text { Difference } \\
P \text { Value }\end{array}$ \\
\hline Age, mean, y & 29.1 & 28.7 & 26.6 & - \\
\hline Race/ethnicity, \% & & & & .001 \\
\hline White & 86.7 & 79.6 & 80.6 & \\
\hline Black & 8.9 & 16.6 & 14.1 & \\
\hline Other/none & 5.2 & 3.8 & 5.3 & \\
\hline Hispanic ${ }^{a}$ & 7.0 & 6.3 & 23.0 & \\
\hline Annual family income, \% & & & & - \\
\hline$<\$ 10,000$ & 13.7 & 19.7 & 17.4 & \\
\hline$\$ 10,000$ to $\$ 49,999$ & 33.1 & 34.4 & 45.3 & \\
\hline$\geq \$ 50,000$ & 50.2 & 43.9 & 34.2 & \\
\hline Not reported & 3.0 & 2.0 & 3.1 & \\
\hline Body mass index, obese, $\%$ & 40.0 & 34.1 & 38.9 & - \\
\hline Secondhand smoke exposure, \% & & & & - \\
\hline Ever $5-7 \mathrm{~d} / \mathrm{wk}$ & 47.0 & 55.4 & 42.1 & \\
\hline Now 5-7 d/wk & 19.4 & 20.4 & 16.8 & \\
\hline Smoking, \% & & & & - \\
\hline Current & 10.3 & 7.6 & 7.4 & \\
\hline Ever & 26.0 & 20.4 & 16.8 & \\
\hline $\begin{array}{l}\text { Activity level: strenuous } \\
\text { activity, \% }\end{array}$ & & & & - \\
\hline$\geq 3$ times/wk, $15 \mathrm{~min}$ & 40.1 & 37.6 & 35.3 & \\
\hline$\geq 5$ times/wk, $15 \mathrm{~min}$ & 20.6 & 17.8 & 17.9 & \\
\hline Allergy tests ever, yes, \% & 51.2 & 53.5 & 48.9 & - \\
\hline $\begin{array}{l}\text { Asthma not in control: } \\
\text { ACT score } \text { s }^{b}<20, \%\end{array}$ & 59.2 & 57.4 & 56.8 & - \\
\hline $\begin{array}{l}\text { Thought they needed asthma } \\
\text { care and could not get it, \% }\end{array}$ & 14.3 & 14.6 & 20.6 & - \\
\hline $\begin{array}{l}\text { Asthma-related visit to ED, } \\
\text { urgent care, or hospital in } \\
6 \text { mo before enrollment, \% }\end{array}$ & 17.5 & 15.9 & 22.1 & - \\
\hline Age-group, \% & & & & - \\
\hline Child (5-11 y) & 21.7 & 18.8 & 30.5 & \\
\hline Adolescent (12-18 y) & 15.8 & 20.2 & 14.2 & \\
\hline Adult (>18 y) & 62.5 & 61.1 & 55.3 & \\
\hline \multicolumn{5}{|c|}{$\begin{array}{l}\text { ACT = Asthma Control Test; APGAR = Activities, Persistent, triGGers, Asthma medications, Response to therapy; } \\
\mathrm{ED}=\text { emergency department. }\end{array}$} \\
\hline \multicolumn{5}{|c|}{ a Only significant difference was proportion Hispanic. } \\
\hline
\end{tabular}


Figure 3. Primary outcomes: asthma-related ED, urgent care, and hospital visits, and asthma control (rates of "in control").

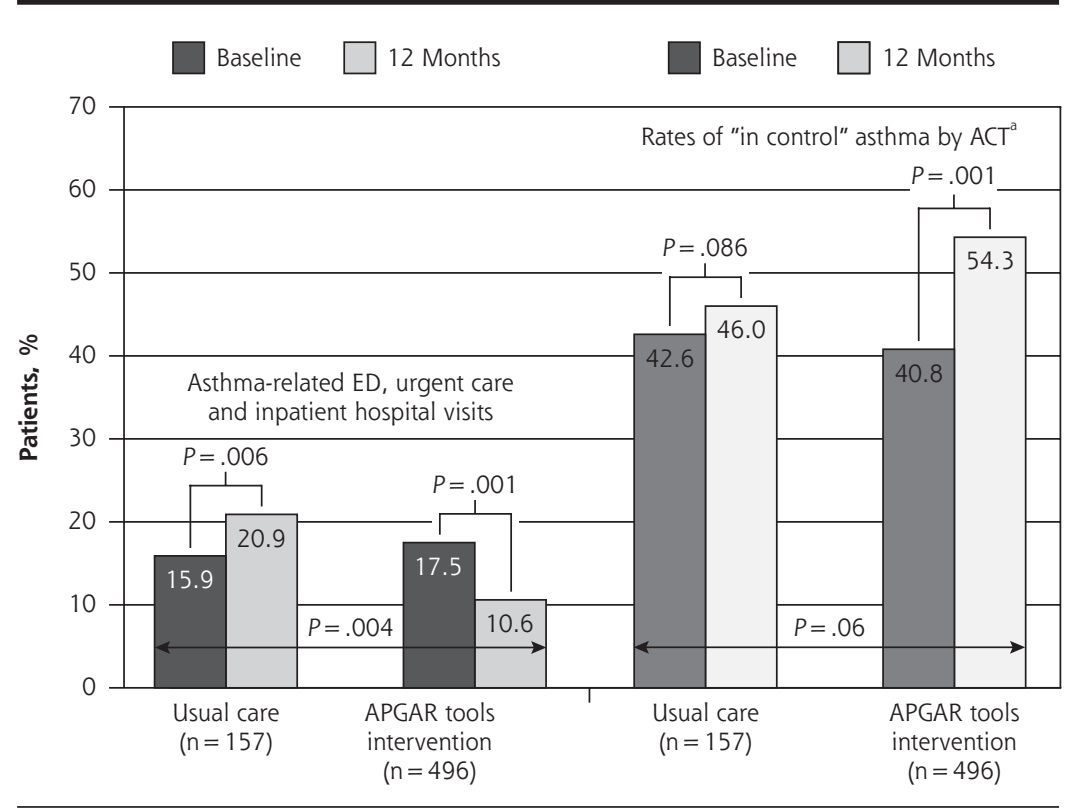

$\mathrm{ACT}=$ Asthma Control Test; APGAR = Activities, Persistent, triGGers, Asthma medications, Response to therapy; $\mathrm{ED}=$ emergency department.

aCT score $\geq 20$

Note: Rates of asthma-related ED, urgent care, and hospital visits compared with $\chi^{2}$ test. Rates of asthma control compared with McNemar test.

\section{DISCUSSION}

In a geographically and socioeconomically diverse group of family medicine and pediatric practices, introduction of the Asthma APGAR tools resulted in a significant decrease in asthma-related ED, urgent care, and hospital visits; a trend toward an increase in the proportion of patients whose asthma was controlled $_{i}$ and increased adherence to asthma guidelines. There was also a trend toward greater improvements in asthmarelated quality-of-life scores among intervention patients. As expected, practice change was reported to be difficult, but the Asthma APGAR tools were perceived to be useful and efficient.

These tools are designed to be used in primary care. Use of the Asthma APGAR tools does not require the addition of nurse managers ${ }^{45}$ community health workers, ${ }^{28}$ or practice facilitators. ${ }^{27}$ Introduction of the tools does require education of practice staff or changes in clinician behavior, which remain barriers to implementation. Introducing a new tool or care system may also have unintended consequences, such as replacing some existing activity with those for the new tool. ${ }^{60}$ The enrolled practices did comment that they were unable to begin other new quality improvement projects for any medical condition for at least the first 6 to 12 months of working to implement the Asthma APGAR tools, but did not believe they eliminated any preexisting practice activities.

The Asthma APGAR tools provide a broad array of information beyond what is included with most control assessments and beyond what is collected in most primary care asthma visits. ${ }^{6,23,31}$ Unlike other assessments for asthma control, these tools highlight multiple reasons for inadequate control, including unrecognized or unavoidable triggers, incomplete adherence to asthma medications, and patient perception of response to therapy that may be due to poor inhaler technique. This enhanced decision support appears to improve patient and practice outcomes, as shown in this study. The favorable changes in asthma control in our study were not accompanied by a statistically significant change in asthma-related quality-of-life scores. This discrepancy likely highlights the different aspect of a patient's life assessed by the domains
Table 2. Barriers to and Facilitators of Practice Implementation of APGAR Tools Captured by Staff Comments

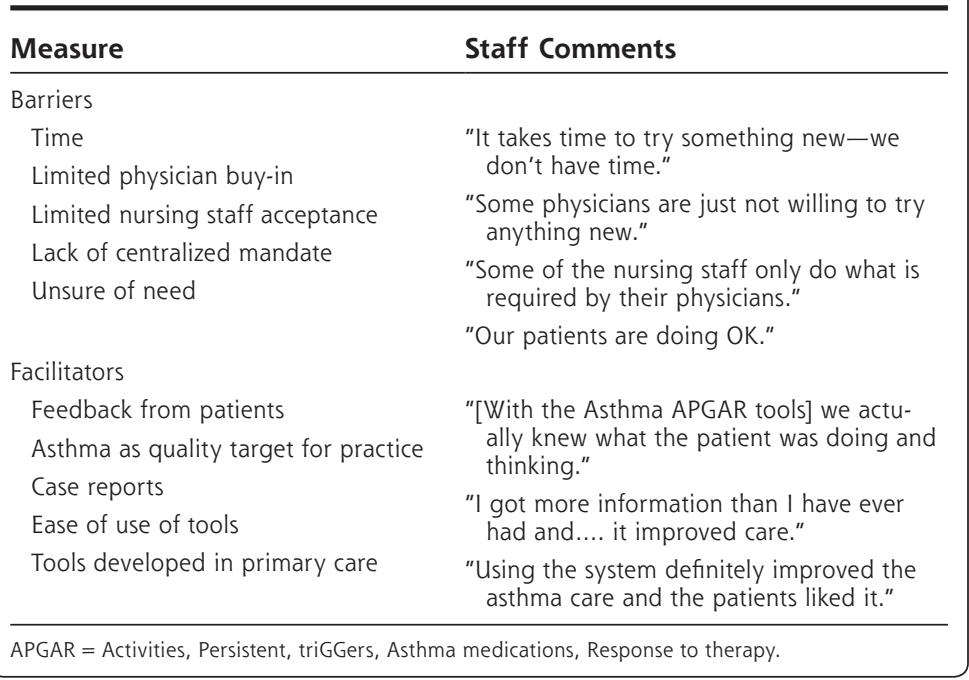


of asthma control and the broader assessment of living with asthma or asthma-related quality-of-life. Use of the Asthma APGAR system was designed to address asthma control and may not improve overall asthmarelated quality of life.

Time pressures and unwillingness to try a new tool have also been barriers reported in many studies of practice improvement programs. ${ }^{34}$ The ability to incorporate the tool into the electronic health record (EHR) as a facilitator is encouraging. Unfortunately, our practices reported that embedding the tools was often expensive and slow, especially if the practice or health system used one of the larger, more established systems with long wait times and high prices charged for these changes. Cave and colleagues ${ }^{29}$ are currently studying the impact of embedding asthma care tools into an EHR and may provide additional data and support for more rapid incorporation of tools.

Lenney and colleagues ${ }^{61}$ highlighted the complex nature of asthma care, health care, and similar barriers of incorporating change into care processes. Perhaps combining our work with that of Cloutier et $\mathrm{al}_{1}{ }^{62}$ who were able to improve pediatricians' readiness to change, would reduce this barrier.

Although studies of asthma quality improvement programs are common, few use randomized trial designs, include patients of all ages, or report patient outcomes. A randomized trial in Quebec primary care practices ${ }^{63}$ used a paper tool to guide physicians' assessment of asthma and demonstrated a 39\% decrease in ED and hospital asthma care. In Spain, Román-Rodríguez et $\mathrm{al}^{30}$ reported on a randomized controlled trial that "slightly" increased use of asthma and COPD patient assessment tools after physician education, but did not assess patient outcomes. Mold et $\mathrm{a}^{27}$ compared implementation of asthma care modifications using practice facilitators, a learning collaborative, and both combined in family medicine practices. Practice facilitator use increased practices' documentation of asthma severity and asthma control, but patient outcomes were not assessed. Studying only children, Lozano and colleagues ${ }^{45}$ reported a $36 \%$ decrease in exacerbation rates by using nurse managers. Home visits by community health workers increased symptomfree days by 2 during the 2 -week assessment period but did not change children's urgent heath care use. ${ }^{28}$

Other reports are limited to children and use only preprogram and postprogram comparisons. ${ }^{36,64-73}$ Ragazzi et $a l^{36}$ were able to improve 4 of 8 care processes, but in exit interviews, staff reported those improvements were unlikely to be sustained without ongoing external support. Adding nurse managers, plus "intense interaction" with families and home visits, both Woods et $\mathrm{al}^{72}$ and Lob et $\mathrm{a}^{169}$ demonstrated a pre-to-post decrease in rates of asthma ED visits $(68 \%$ and $70 \%$, respectively), whereas Bunik et $\mathrm{a}^{64}$ and Vernacchio et $\mathrm{al}^{68}$ used similar methods but found no improved outcomes, with improvement only in documentation of care processes. Okelo and colleagues ${ }^{12}$ highlighted the lack of studies that assessed patient outcomes even when introducing intensive external practice support. In contrast, we found that the Asthma APGAR tools improved patient outcomes and requires little additional practice support.

Our study has both strengths and limitations. The practices we included represent a diverse segment of the US population based on geography, race, ethnicity, and socioeconomic status. Study sites were primarily smaller, non-inner city practices. The results may not be generalizable to large health care systems. Such systems, however, often have greater support for quality improvement initiatives, including the ability to embed the tools into the EHR.

We included only patients aged 5 to 45 years, which may limit the generalizability of the results to older adults with asthma. At the time of the study inception, concerns regarding misdiagnosis of COPD were well spelled out in the literature, and early discussions of asthma-COPD overlap further highlighted the potential differences in treatments and patient assessment methods in adults older than 45 years. ${ }^{52}$

Although the pragmatic nature of our trial enhances the generalizability of its results, it may also have reduced survey response rates because of limited interaction of patients with the research team, and may have achieved less practice change than could be achieved with greater practice support or intervention. ${ }^{27}$ We did not specifically evaluate a practice's readiness to change. Doing so may be a very important precursor to successful widespread implementation. Learning how to enhance readiness to change and acceptance of change may be even more important.

Our primary outcomes of health care use, asthma control, and asthma-related quality of life are patient reported and therefore may be subject to recall bias. In addition, outcomes can be obtained only from patients who completed questionnaires; therefore, responder bias is possible. Differences in how practices document may also introduce bias, given that the EHR is used to measure some outcomes. Our cluster-randomized study design helped reduce the risk of these bias types when comparing intervention and usual care practices. In addition, the lack of significant differences between respondents and nonrespondents on characteristics at baseline reduces the concerns about our moderate response rates. The presence and frequency of asthma exacerbations were patient reported. Because of limitations in the enrolled clinics' electronic and billing 
systems, we were unable to ensure capture of information on all use of systemic steroid bursts ${ }^{74}$ or confirm all ED, urgent care, and hospital visits, which often occurred outside of the practice site. Limiting our practices to those with prescription-fulfillment data or those belonging to large health systems allowing EHR confirmation of most ED and hospital visits would have limited the types of practices we could have enrolled, decreasing generalizability to our target rural and smaller practices.

In conclusion, introduction of the Asthma APGAR tools improved asthma control; reduced asthma-related $\mathrm{ED}$, urgent care, and hospital visits; and improved practices' asthma guideline adherence, suggesting that these tools are an effective practice addition for asthma management in the primary care setting. Future studies will need to assess the impact of introducing the Asthma APGAR tools into the primary care practices of large health care systems.

To read or post commentaries in response to this article, see it online at http://www.AnnFamMed.org/content/16/2/100.

Key words: asthma; asthma control, outcomes; asthma management; primary care; pragmatic research; practice-based research; protocol; implementation; guideline; asthma tool; randomized clinical trial

Submitted April 24, 2017; submitted, revised, September 19, 2017; accepted September 26, 2017.

Funding support: This work was supported by AHRQ grant R01HS 008745, Barbara P. Yawn, Principal Investigator. Barbara P. Yawn has also received research grants from NIH and PCORI for asthma and COPD research. Young Juhn received support for asthma research from an $\mathrm{NIH}$ funded R01 grant (R01 HL126667), an R21 grant (R21Al116839-01), the T. Denny Sanford Pediatric Collaborative Research Fund, and a Scholarly Clinician Award from the Mayo Foundation. Matthew A. Rank received support for asthma research from the AHRQ (grant R03 HS022126).

Previous presentations: Preliminary results were presented as a latebreaking poster at the American Academy of Allergy, Asthma \& Immunology (AAAAI) meeting; March 2017; Atlanta, Georgia.

Trial registration: NCT01446315 at clinicaltrials.gov.

Supplementary materials: Available at http://www.AnnFamMed. org/content/16/2/100/suppl/DC1/.

\section{References}

1. Hedman L, Bjerg A, Lundbäck B, Rönmark E. Conventional epidemiology underestimates the incidence of asthma and wheeze-a Iongitudinal population-based study among teenagers. Clin Transl Allergy. 2012;2(1):1.

2. Akinbami LJ, Sullivan SD, Campbell JD, et al. Asthma outcomes: healthcare utilization and costs. J Allergy Clin Immunol. 2012;129(3) (Suppl):S49-S64.

3. Bloom B, Cohen RA, Freeman G. Summary health statistics for U.S. children: National Health Interview Survey, 2009. Vital Health Stat 10. $2010 ; 247(247): 1-82$.
4. Lozano P, Sullivan SD, Smith DH, Weiss KB. The economic burden of asthma in US children: estimates from the National Medical Expenditure Survey. J Allergy Clin Immunol. 1999;104(5):957-963.

5. To T, Dell S, Dick P, Cicutto L. The burden of illness experienced by young children associated with asthma: a population-based cohort study. J Asthma. 2008;45(1):45-49.

6. Yawn BP, Rank MA, Cabana MD, Wollan PC, Juhn YJ. Adherence to asthma guidelines in children, tweens, and adults in primary care settings: a practice-based network assessment. Mayo Clin Proc. 2016;91(4):411-421.

7. Rowe $B H$, Voaklander $\mathrm{DC}$, Wang $\mathrm{D}$, et al. Asthma presentations by adults to emergency departments in Alberta, Canada: a large population-based study. Chest. 2009;135(1):57-65.

8. Henderson AJ. What have we learned from prospective cohort studies of asthma in children? Chron Respir Dis. 2008;5(4):225-231.

9. Nathan RA, Meltzer EO, Blaiss MS, Murphy KR, Doherty DE, Stoloff SW. Comparison of the Asthma in America and Asthma Insight and Management surveys: did asthma burden and care improve in the United States between 1998 and 2009? Allergy Asthma Proc. 2012; 33(1):65-76.

10. Podjasek JC, Rank MA. Have expert guidelines made a difference in asthma outcomes? Curr Opin Allergy Clin Immunol. 2013;13(3): 237-243.

11. Brown M, Phillips CB, Ciszek K, et al. Children in the ACT with asthma - are they taking preventer medication according to guidelines? Aust Fam Physician. 2010;39(3):146-149.

12. Okelo SO, Butz AM, Sharma R, et al. Interventions to modify health care provider adherence to asthma guidelines: a systematic review. Pediatrics. 2013;132(3):517-534.

13. Murray CJ, Atkinson C, Bhalla K, et al.; U.S. Burden of Disease Collaborators. The state of US health, 1990-2010: burden of diseases, injuries, and risk factors. JAMA. 2013;310(6):591-608.

14. National Heart, Lung, and Blood Institute. National Asthma Education and Prevention Expert Panel report 3: guidelines for the diagnosis and management of asthma. Bethesda, MD: National Institutes of Health. http://www.nhlbi.nih.gov/files/docs/guidelines/ asthgdln.pdf. Published Aug 28, 2007. Accessed Feb 24, 2018.

15. Vollmer WM. Assessment of asthma control and severity. Ann Allergy Asthma Immunol. 2004;93(5):409-413, quiz 414-416, 492.

16. Vollmer WM, Markson LE, O'Connor E, Frazier EA, Berger M, Buist AS. Association of asthma control with health care utilization: a prospective evaluation. Am J Respir Crit Care Med. 2002;165(2):195-199.

17. Nathan RA, Sorkness CA, Kosinski M, et al. Development of the asthma control test: a survey for assessing asthma control. J Allergy Clin Immunol. 2004;113(1):59-65.

18. Schatz M, Nakahiro R, Jones $\mathrm{CH}$, Roth RM, Joshua A, Petitti D. Asthma population management: development and validation of a practical 3-level risk stratification scheme. Am J Manag Care. 2004; 10(1):25-32.

19. Juniper EF. Assessing asthma control. Curr Allergy Asthma Rep. 2007; 7(5):390-394.

20. Schatz M, Zeiger RS, Vollmer WM, Mosen D, Cook EF. Determinants of future long-term asthma control. J Allergy Clin Immunol. 2006;118(5):1048-1053.

21. Juniper EF, Svensson K, Mörk AC, Ståhl E. Measurement properties and interpretation of three shortened versions of the asthma control questionnaire. Respir Med. 2005;99(5):553-558.

22. Schatz M, Mosen DM, Kosinski M, et al. Predictors of asthma control in a random sample of asthmatic patients. J Asthma. 2007:44(4): 341-345.

23. Yawn BP, Brenneman SK, Allen-Ramey FC, Cabana MD, Markson LE. Assessment of asthma severity and asthma control in children. Pediatrics. 2006;118(1):322-329. 
24. Skinner EA, Diette GB, Algatt-Bergstrom PJ, et al. The Asthma Therapy Assessment Questionnaire (ATAQ) for children and adolescents. Dis Manag. 2004;7(4):305-313.

25. Pinnock $H$, Sheikh A, Juniper EF. Evaluation of an intervention to improve successful completion of the Mini-AQLQ: comparison of postal and supervised completion. Prim Care Respir J. 2004;13(1): 36-41.

26. Yawn BP. Pulmonary Practice Pearls for Primary Care Physicians. 13-part eNewsletter series. J Fam Pract. 2016;65(1)(Suppl): supp_az_0116.

27. Mold JW, Fox C, Wisniewski A, et al. Implementing asthma guidelines using practice facilitation and local learning collaboratives: a randomized controlled trial. Ann Fam Med. 2014;12(3):233-240.

28. Krieger J, Song L, Philby M. Community health worker home visits for adults with uncontrolled asthma: the HomeBASE Trial randomized clinical trial. JAMA Intern Med. 2015;175(1):109-117.

29. Cave AJ, Sharpe H, Anselmo M, et al. Primary Care Pathway for Childhood Asthma: protocol for a randomized cluster-controlled trial. JMIR Res Protoc. 2016;5(1):e37.

30. Román-Rodríguez M, Pardo MG, Lopez LG, Ruiz AU, van Boven JFM. Enhancing the use of Asthma and COPD Assessment Tools in Balearic Primary Care (ACATIB): a region-wide cluster-controlled implementation trial. NPJ Primary Care Respir Med. 2016;(26): 16003.

31. Cabana MD, Slish KK, Nan B, Lin X, Clark NM. Asking the correct questions to assess asthma symptoms. Clin Pediatr (Phila). 2005; 44(4):319-325.

32. Yawn BP, Wollan P, Kurland M, Scanlon P. A longitudinal study of the prevalence of asthma in a community population of school-age children. J Pediatr. 2002;140(5):576-581.

33. Diette GB, Patino CM, Merriman B, et al. Patient factors that physicians use to assign asthma treatment. Arch Intern Med. 2007;167(13): 1360-1366.

34. Cabana MD, Rand CS, Becher OJ, Rubin HR. Reasons for pediatrician nonadherence to asthma guidelines. Arch Pediatr Adolesc Med. 2001;155(9):1057-1062.

35. Herman EJ, Garbe PL, McGeehin MA. Assessing community-based approaches to asthma control: the Controlling Asthma in American Cities Project. J Urban Health. 2011;88(Suppl 1):1-6.

36. Ragazzi H, Keller A, Ehrensberger R, Irani AM. Evaluation of a practice-based intervention to improve the management of pediatric asthma. J Urban Health. 2011;88(Suppl 1):38-48.

37. Yawn BP, Bertram S, Wollan P. Introduction of Asthma APGAR tools improve asthma management in primary care practices. J Asthma Allergy. 2008;1:1-10.

38. Rank MA, Bertram S, Wollan P, Yawn RA, Yawn BP. Comparing the Asthma APGAR system and the Asthma Control Test ${ }^{\text {TM }}$ in a multicenter primary care sample. Mayo Clin Proc. 2014;89(7):917-925.

39. Nutting PA, Beasley JW, Werner JJ. Practice-based research networks answer primary care questions. JAMA. 1999;281(8):686-688.

40. Pace WD, Fagnan LJ, West DR. The Agency for Healthcare Research and Quality (AHRQ) Practice-Based Research Network (PBRN) relationship: delivering on an opportunity, challenges, and future directions. J Am Board Fam Med. 2011;24(5):489-492.

41. Westfall JM, Mold J, Fagnan L. Practice-based research-"Blue Highways" on the NIH roadmap. JAMA. 2007;297(4):403-406.

42. Woolf SH. The meaning of translational research and why it matters. JAMA. 2008;299(2):211-213.

43. Solberg LI, Kottke TE, Brekke ML. Quality improvement in primary care: The role of organization, collaboratives, and managed care. In: McLaughlin $\mathrm{CP}$, Kalunzny AD, eds. Continuous Quality Improvement in Head Care: Theory, Implementation, and Applications. 3rd ed. Gaithersburg, MD: Aspen Publishers; 2005:297-317.
44. Homer CJ, Forbes P, Horvitz L, Peterson LE, Wypij D, Heinrich P. Impact of a quality improvement program on care and outcomes for children with asthma. Arch Pediatr Adolesc Med. 2005;159(5): 464-469.

45. Lozano P, Finkelstein JA, Carey VJ, et al. A multisite randomized trial of the effects of physician education and organizational change in chronic-asthma care: health outcomes of the Pediatric Asthma Care Patient Outcomes Research Team II Study. Arch Pediatr Adolesc Med. 2004;158(9):875-883.

46. Yawn BP, Bertram S, Kurland M, et al. Protocol for the asthma tools study: a pragmatic practice-based research network trial. Pragmat Obs Res. 2013;4:7-18.

47. Schatz M, Kosinski M, Yarlas AS, Hanlon J, Watson ME, Jhingran P. The minimally important difference of the Asthma Control Test. J Allergy Clin Immunol. 2009;124(4):719-723.e1.

48. Yawn BP, Wollan PC, Bertram SL, et al. Asthma treatment in a population-based cohort: putting step-up and step-down treatment changes in context. Mayo Clin Proc. 2007;82(4):414-421.

49. Winklerprins V, Walsworth DT, Coffey JC. Clinical Inquiry. How best to diagnose asthma in infants and toddlers? J Fam Pract. 2011;60(3): 152-154.

50. Rodriguez-Martinez CE, Sossa-Briceño MP, Castro-Rodriguez JA Discriminative properties of two predictive indices for asthma diagnosis in a sample of preschoolers with recurrent wheezing. Pediatr Pulmonol. 2011;46(12):1175-1181.

51. Miravitlles M, Andreu I, Romero Y, Sitjar S, Altés A, Anton E. Difficulties in differential diagnosis of COPD and asthma in primary care. Br J Gen Pract. 2012;62(595):e68-e75.

52. Postma DS, Rabe KF. The Asthma-COPD Overlap Syndrome. N Engl J Med. 2015;373(13):1241-1249.

53. D'Urzo AD. Must family physicians use spirometry in managing asthma patients?: NO. Can Fam Physician. 2010;56(2):127, 129, 131، 133; discussion e50, e52.

54. Kaplan HC, Brady PW, Dritz MC, et al. The influence of context on quality improvement success in health care: a systematic review of the literature. Milbank Q. 2010;88(4):500-559.

55. Holton C, Crockett A, Nelson M, et al. Does spirometry training in general practice improve quality and outcomes of asthma care? Int $J$ Qual Health Care. 2011;23(5):545-553.

56. Juniper EF, Guyatt GH, Willan A, Griffith LE. Determining a minimal important change in a disease-specific Quality of Life Questionnaire. J Clin Epidemiol. 1994;47(1):81-87.

57. National Health Interview Survey. Questionnaires, Datasets, and Related Documentation. https://www.cdc.gov/nchs/nhis/nhis questionnaires.htm. Published Jun 26, 2017. Accessed Sep 1, 2017.

58. Yawn BP, Wollan P. Interrater reliability: completing the methods description in medical records review studies. Am J Epidemiol. 2005; 161(10):974-977.

59. Yawn BP, Rank MA, Bertram SL, Wollan PC. Obesity, low levels of physical activity and smoking present opportunities for primary care asthma interventions: an analysis of baseline data from The Asthma Tools Study. NPJ Prim Care Respir Med. 2015;25:15058.

60. Williams RL, Stange K, Phillips WR, et al. Encouraging innovation, unintended consequences, and group-level research. Ann Fam Med. 2013;11(3):200-202.

61. Lenney W, Clayton S, Gilchrist FJ, et al. Lessons learnt from a primary care asthma improvement project. NPJ Prim Care Respir Med. 2016;26:15075

62. Cloutier MM, Tennen H, Wakefield DB, Brazil K, Hall CB. Improving clinician self-efficacy does not increase asthma guideline use by primary care clinicians. Acad Pediatr. 2012;12(4):312-318.

63. Renzi PM, Ghezzo H, Goulet S, Dorval E, Thivierge RL. Paper stamp checklist tool enhances asthma guidelines knowledge and implementation by primary care physicians. Can Respir J. 2006;13(4):193-197. 
64. Bunik M, Federico MJ, Beaty B, Rannie M, Olin JT, Kempe A. Quality improvement for asthma care within a hospital-based teaching clinic. Acad Pediatr 2011;11(1):58-65.

65. Gold J, Reyes-Gastelum D, Turner J, Davies HD. A quality improvement study using fishbone analysis and an electronic medical records intervention to improve care for children with asthma. Am J Med Qual. 2014;29(1):70-77.

66. Bereznicki B, Peterson G, Jackson S, Walters EH, Gee P. The sustainability of a community pharmacy intervention to improve the quality use of asthma medication. J Clin Pharm Ther. 2011; 36(2): 144-151.

67. Kaferle JE, Wimsatt LA. A team-based approach to providing asthma action plans. J Am Board Fam Med. 2012;25(2):247-249.

68. Vernacchio L, Francis ME, Epstein DM, et al. Effectiveness of an asthma quality improvement program designed for maintenance of certification. Pediatrics. 2014;134(1):e242-e248.
69. Lob SH, Boer JH, Porter PG, Núñez D, Fox P. Promoting best-care practices in childhood asthma: quality improvement in community health centers. Pediatrics. 2011;128(1):20-28.

70. Butz AM, Halterman J, Bellin M, et al. Improving preventive care in high risk children with asthma: lessons learned. J Asthma. 2014; 51(5):498-507.

71. Nkoy F, Fassl B, Stone B, et al. Improving pediatric asthma care and outcomes across multiple hospitals. Pediatrics. 2015;136(6): e1602-e1610.

72. Woods ER, Bhaumik U, Sommer SJ, et al. Community asthma initiative: evaluation of a quality improvement program for comprehensive asthma care. Pediatrics. 2012;129(3):465-472.

73. Selroos $O$, Kupczyk M, Kuna P, et al. National and regional asthma programmes in Europe. Eur Respir Rev 2015;24(137):474-483.

74. Fuhlbrigge A, Peden D, Apter AJ, et al. Asthma outcomes: exacerbations. J Allergy Clin Immunol. 2012;129(3)(Suppl):S34-S48.

\section{CHANGE-OF-ADDRESS FORM FAMILY MEDICINE}

Please complete this form and mail to the following address or fax to Annals Circulation at 913-906-6080:

Annals of Family Medicine, Circulation Department, 11400 Tomahawk Creek Pkwy, Leawood, KS 66211-2680

Check if member of sponsoring organization:

$$
\begin{array}{ll}
\square \text { AAFP } \square \text { ABFM } \square \text { STFM } \square \text { ADFM } \\
\square \text { AFMRD } \square \text { NAPCRG } \square \text { CFPC }
\end{array}
$$

ID number from label on your journal cover

OLD Information (Please print.)

\begin{tabular}{ll}
\hline Name \\
\hline Company (if applicable) \\
\hline Address (Street plus Apt or Ste) \\
\hline City & Postal Code (9-digit ZIP for US) \\
\hline Country & Fax \\
\hline Telephone & \\
\hline E-Mail &
\end{tabular}

NEW Information (Please print.)

\begin{tabular}{lc}
\hline Name \\
\hline Company (if applicable) \\
\hline Address (Street plus Apt or Ste) \\
\hline City & \\
\hline Country & Postal Code (9-digit ZIP for US) \\
\hline Telephone & Fax \\
\hline E-Mail &
\end{tabular}

